\section{Investigation on Five Years (2010 - 2014) Food Poisonings Recorded in Bamenda and NDOP Public Hospitals in Cameroon}

\section{Abstract}

Background and Context: In Cameroon, food poisoning has become a public health concern.

Objectives: This study aimed to provide information on food poisoning cases recorded in four (4) main public hospitals (Regional Hospital Bamenda, Bambui Health District, PMI Hospital and Ndop Health District) of the North-West Region, from 2010 to 2014.

Methods: The collection of data was based on extracting patient's information from daily record books of the hospitals using a form. Data analysis was performed using statistical software package SPSS 16.0.

Results: Among 323,169 persons consulted, 252 peoples were poisoned through food: $48 \%$ women and $52 \%$ men aged between 1 and 70 years with highest number raging between 5 and 35 years old (85\%); the year 2011 recorded the highest number of food intoxicated patients (26\%), most of the patients were farmers and students; Bamenda Regional Hospital scored the highest number (42\%); Mile 4, Bambui and Akum were sectors presenting the highest number of residents (total of $27 \%$ ); pesticides were the most frequent toxic, over the 252 people consulted, only $75 \%$ recovered; the most frequent symptoms were vomiting, diarrhea, stomachache and headache; foods consumed were indigenous (Achu, fufu corn, fresh cassava, plantains, sweet potatoes, beans, meat among others) and water; treatment given was indigenous (milk, red oil and charcoal) or adequate medicines once received in the hospital.

Conclusion: Education on good hygienic practices becomes necessary for the population and farmers should be trained on handling, manipulating and storing pesticides methods.

Keywords: Food poisoning; Hospital records; Patients; Symptoms
Jean $\mathrm{S}^{1 *}$, Michel $\mathrm{A}^{2}$ and Benoit $\mathrm{NM}^{2}$

\author{
1 Department of Social Economy and \\ Family Management, HTTTC, University \\ of Bamenda, Bamenda, Cameroon \\ 2 Department of Applied Chemistry, \\ ENSAI, University of Ngaoundere, \\ Ngaoundéré, Cameroon
}

*Corresponding author: Dr. Jean Sonchieu

झ jsonchieu@yahoo.fr; sonchieujean@gmail.com

Department of Social Economy and Family Management, HTTTC, University of Bamenda, Bamenda-39, Cameroon.

Tel: +23722816550

Citation: Jean S, Michel A, Benoit NM (2018) Investigation on Five Years (2010 - 2014) Food Poisonings Recorded in Bamenda and NDOP Public Hospitals in Cameroon. Insights Biomed. Vol.3 No.2:9

\section{Introduction}

The rapid population growth in rural and urban areas of Cameroon and the change in dietary habits of most Cameroonians have made the demand of food to remain on a constant increase. This needs constant food production. But cropping is seasonal and will influence the food security parameters. To overcome this obstacle, food should be stored at least for six months using various methods that include insecticides, fungicides and rodenticides application [1]. Some food, however, are highly perishable due to rapid growth of micro-organisms which may be harmful to humans [2]. The presence of pathogenic microorganisms or chemicals in food may render it poisonous and unfit for human consumption [3]. In the North West region of Cameroon, agro-chemicals are extensively used for farming in various areas and can constitute a real threat for consumers because of their toxicity properties [4-6]. Food poisoning generally occurs when food contaminated by pathogenic microorganisms or by chemicals is ingested $[7,8]$. This can induce serious health issue or death as mentioned by Toldrá et al. [9]. The poison can affect and disrupts a particular function in the 
consumer like Central Nervous System Effects, reproductive system, kidneys, and liver.

It has been observed that there is an increasing rate of food poisoning in recent years. About 20 million worldwide reported including 11 million found in Africa and 1 million cases in Cameroon by year 2003 [10,11]. 1.2 million cases have been reported in Cameroon attributed to various origins: chemicals, microorganisms, excess alcohol etc. The most commonly reported cases are caused by Campylobacter and Salmonella bacteria and pesticides [12]. Most cases happened accidently (when ingesting contaminated food or when manipulating pesticides or unconsciously after eating contaminated food) and suicide cases can also be observed $[13,14]$. In North-West Region of Cameroon, food mostly involved with poisoning are meat, dairy products, poultry, cooked food such as achu, garri, rice and egusi soup, fufu and djamajama, water fufu and eru and some ready-to-eat food like [15].

The chemical food poisoning cases were reported occurring when food is contaminated by chemicals such as pesticides and preservatives [16]. There is a growing number of pesticide uses in rural and urban areas but knowledge on safety measures among users remains poor [17]. Risk factors such as Poor handling, spraying, and product quality and disposal methods of chemicals have risen in Cameroon [5]. They have led to many poisoning cases. Furthermore, poor hygienic practices during cooking can be pointed out since poisoning from microbiological source is considered to be very frequent in Africa [2]. These factors affect different social groups such as farmers, children, students who are reported in hospitals or not depending on the transportation and financial means, gravity of the case and promptitude of family members. The aim of this study was to investigate on cases of food intoxication reported in four main local public hospitals in North-West Region of Cameroon.

\section{Material and Methods}

\section{Area of study}

The area of study was Bamenda municipality main public hospitals and one from neighboring main city (Ndop). Bamenda is the regional capital of the North West Region found in the western highlands of Cameroon. It lies between latitudes $5^{\circ}$ $40^{\prime}$ and $7^{\circ}$ to the North of the equator, and between longitudes $9^{\circ} 45$ and $11^{\circ} 10^{\prime}$ to the East of the Meridian [18]. The National Institute of Statistics: North West Branch [19] estimated its total population at about 1,728,953 (one million seven hundred and twenty-eight thousand nine hundred and fifty-three) inhabitants, with a growth rate of $1.8 \%$. It has about 26 public and private hospitals settled in twenty health districts [19]. The main public hospitals involved in this study are: The Bamenda Regional Hospital, PMI of Bamenda, Bambui District Hospital of and Ndop District Hospital. They were selected based on skill of personnel to handle critical health issues. It is important to notice that, the North West Region has a total number of 1,131 (one thousand one hundred and thirty-one) health personnel [19].

\section{Data collection}

The authorities of the respective hospitals issued an authorization letter permitting to get access on record books in the various services. Identification of poisoned cases was based on records found in the four main public hospitals and followed by admitted patients files (recovered or death). Data were reported in a form designed for the purpose and included poisoning dates, poisoning issues, ages and gender of the patients, routes of poisoning, residences, tribes, admission issues, types of food involved, occupations, signs and symptoms. The period covered was between January 2010 and December 2014 because no data was available since 2010 .

\section{Statistical analysis}

Data from the records were manually reported in a form, codified, computerized and processed. Data analysis was performed using statistical software package SPSS 16.0. Excel 2010 was for computerizing. A descriptive statistical analysis was done to generate frequencies and tables. A non-parametric test, Chi square test, was performed to identify possible relations with a $p$-value of $<0.05$ considered to be statistically significant. Factors (variables) were those mentioned above were reported on the form.

\section{Results and Discussion}

\section{Identification of patients}

A total of 252 individuals were recorded to be intoxicated after consuming food between 2010 and 2014. The largest number (42\%) was transported to the Regional Hospital while other health institutions recoded at 22, 10, and 26\% for Bambui Health District, PMI Hospital and NDOP Health district respectively. Table 1 shows that more males (52\%) were poisoned than females (48\%). From the same Table 1, $85 \%$ of the affected populations have less than thirty-five years. Only one person was aged above 65 while the least aged were children of less than two years (5\%). They were Carpenters, Children (school or not), Drivers, Farmer, Students, Traders and other occupations including mechanics, civil servants. But the most represented groups were farmers (32\%) and students (29\%). No statistical significance differences were gotten between various groups (Chi-square; values $P$ values: $0.650 ; 1.000)$ and sexes (Chi-square; values $P$ values: $0.657 ; 1.000)$

\section{Residence of food intoxicated patients}

Food poisoned patients come from many sectors of the city with representation varying between $1 \%$ and $13 \%$ (Table 2). Mile 4 Nkwen is the sector that provide more patients (13\%) followed by Bambui, Ndop and Akum sectors ( $8 \%, 7 \%$ and $6 \%$ respectively). The remaining sectors are almost equally represented (from 1 to $3 \%$ of the total number) and other sectors which were not mentioned in this study because of their low representations. The Regional Hospital received the greatest number of patients who at times come from zones with health center. This is observed from Bambui and Bambili which are nearest to Bambui District Hospital. No statistical significance differences were observed between residences (Chi-square; values P values: $0.750 ; 1.000$ ). 
Table 1 Characteristics of the study population.

Sex Age (years)

Occupation

Area Male Female [2-20] [20-38] [38-56] [56-74] Trader Carpenter Child Driver Farmer Student Others Total intoxications

\begin{tabular}{|c|c|c|c|c|c|c|c|c|c|c|c|c|c|c|}
\hline Bambui DH & 28 & 28 & 20 & 28 & 7 & 1 & 5 & 2 & 7 & 4 & 15 & 12 & 3 & $56(22)$ \\
\hline $\begin{array}{c}\text { Bamenda } \\
\text { RH }\end{array}$ & 57 & 50 & 53 & 38 & 9 & 7 & 10 & 7 & 10 & 6 & 40 & 30 & 8 & $107(42)$ \\
\hline PMI H & 13 & 11 & 20 & 4 & 0 & 0 & 2 & 2 & 7 & 4 & 15 & 20 & 5 & $24(10)$ \\
\hline Ndop DH & 33 & 32 & 34 & 19 & 8 & 4 & 5 & 1 & 7 & 2 & 11 & 10 & 1 & $65(26)$ \\
\hline Total & $\begin{array}{l}131 \\
(52)\end{array}$ & $\begin{array}{l}121 \\
(48)\end{array}$ & $\begin{array}{l}127 \\
(50)\end{array}$ & $89(35)$ & $24(10)$ & $11(5)$ & $23(9)$ & $12(5)$ & $\begin{array}{c}31 \\
(12)\end{array}$ & $16(6)$ & $81(32)$ & $72(29)$ & $17(7)$ & $252(100)$ \\
\hline Chi-square & \multicolumn{2}{|c|}{0.657} & \multicolumn{4}{|c|}{0.657} & \multicolumn{7}{|c|}{0.650} & 0.655 \\
\hline P-values & \multicolumn{2}{|c|}{1.000} & \multicolumn{4}{|c|}{1.000} & \multicolumn{7}{|c|}{1.000} & 1 \\
\hline
\end{tabular}

Note: Legend: Values enclosed in parentheses are percentages (\%).

Table 2 Residence of intoxicated patients.

\begin{tabular}{|c|c|c|c|c|c|}
\hline \multirow{2}{*}{ Residence sector } & \multicolumn{4}{|c|}{ Hospitals } & \multirow{2}{*}{ Total } \\
\hline & PMI & Bambui DH & Bamenda RH & Ndop DH & \\
\hline GTHS & 2 & 3 & 0 & 0 & $5(2)$ \\
\hline Mile 3 & 1 & 5 & 3 & 0 & $9(4)$ \\
\hline Mile 4 & 8 & 10 & 16 & 0 & $34(13)$ \\
\hline Necast & 3 & 0 & 0 & 0 & $3(1)$ \\
\hline Ntasen & 1 & 0 & 2 & 0 & $3(1)$ \\
\hline Old Town & 1 & 0 & 7 & 0 & $8(3)$ \\
\hline Mile 2 & 3 & 0 & 2 & 0 & $5(2)$ \\
\hline Bafurkom & 0 & 2 & 0 & 0 & $2(1)$ \\
\hline Bambili & 0 & 3 & 2 & 0 & $5(2)$ \\
\hline Bambui & 0 & 14 & 5 & 0 & $19(8)$ \\
\hline Babanki & 0 & 3 & 0 & 0 & $3(1)$ \\
\hline Lih & 0 & 3 & 0 & 0 & $3(1)$ \\
\hline Sabga & 0 & 3 & 0 & 0 & $3(1)$ \\
\hline Tikebeng & 0 & 2 & 0 & 0 & $2(1)$ \\
\hline Akum & 0 & 0 & 16 & 0 & $16(6)$ \\
\hline Bafut & 0 & 0 & 8 & 0 & $8(3)$ \\
\hline Bali & 0 & 0 & 2 & 0 & $2(1)$ \\
\hline Balki & 0 & 0 & 2 & 0 & $2(1)$ \\
\hline Bamali & 0 & 0 & 2 & 5 & $7(3)$ \\
\hline Necast & 0 & 0 & 4 & 0 & $4(2)$ \\
\hline City Chemist & 0 & 0 & 4 & 0 & $4(2)$ \\
\hline Commercial & 0 & 0 & 4 & 0 & $4(2)$ \\
\hline Djonkou & 0 & 0 & 2 & 0 & $2(1)$ \\
\hline Foncha-Street & 0 & 0 & 3 & 0 & $3(1)$ \\
\hline Food Market & 0 & 0 & 4 & 0 & $4(2)$ \\
\hline Mile 9 & 0 & 0 & 3 & 0 & $3(1)$ \\
\hline Santa & 0 & 0 & 8 & 0 & $8(3)$ \\
\hline Upstation & 0 & 0 & 3 & 0 & $3(1)$ \\
\hline Funkine & 0 & 0 & 0 & 3 & $3(1)$ \\
\hline Komowa & 0 & 0 & 0 & 2 & $2(1)$ \\
\hline meyong & 0 & 0 & 0 & 3 & $3(1)$ \\
\hline Mighang & 0 & 0 & 0 & 6 & $6(2)$ \\
\hline Ndawara & 0 & 0 & 0 & 3 & $3(1)$ \\
\hline Ndop & 0 & 0 & 0 & 18 & $18(7)$ \\
\hline Njinlagant & 0 & 0 & 0 & 2 & $2(1)$ \\
\hline Nlolow & 0 & 0 & 0 & 5 & $5(2)$ \\
\hline Tokop & 0 & 0 & 0 & 4 & $4(2)$ \\
\hline Tonbo & 0 & 0 & 0 & 2 & $2(1)$ \\
\hline Tuila & 0 & 0 & 0 & 5 & $5(2)$ \\
\hline Others & 5 & 5 & 5 & 7 & $22(9)$ \\
\hline Chi-square & & & 0.750 & & \\
\hline$P$-values & & & 1.000 & & \\
\hline Vote: Values enclosed & $s$ are & & & & \\
\hline
\end{tabular}


Five years evolution in food poisonings and symptoms among patients

According to records books from the four public hospitals, between 2010 and 2014, food poisoning was varying between 12 and $26 \%$. The least record was obtained in 2014 (12\%) while the highest number was registered in 2011 (26\%) while records realized in 2012, 2013 and 2010 were closer (17\%, 21\% and $24 \%$ respectively). These figures also show the situations where patients were admitted or not according to the severity of the case. Thus, among 252 cases recorded, 53\% were not admitted while $47 \%$ were admitted in the hospitals for at least two days. It is important to note that patients who were not admitted may be due to the death of the patients or quick mastering of the case. Among them, $75 \%$ recovered and returned to their respective houses while $25 \%$ died. Statistics did not show any significance differences of symptoms amongst years (Chi-square, values p-values: $0.297,6.475)$.
Symptoms met among food poisoned patients were varying and the most observed were: vomiting (29\%), Diarrhea (20\%), stomachache $(15 \%)$, cough $(10 \%)$ and headache $(8 \%)$. Other symptoms presented by patients were: nausea, cramp, fatigue and others such as mouth and skin irritations, sweating and blurred eyes. Statistics did not indicate any significance differences of symptoms amongst patients (Chi-square; values p-values: $0.258 ; 5.455)$.

\section{Contaminants, foods involved, and treatment administered}

Contaminants/poisons declared by food intoxicated persons or their caretakers were pesticides, food itself or unknown causes. Table 3 shows that pesticides, not including rodenticides (6\%), represent $45 \%$ of the total intoxicating cases. Many causes were not known while other causes such as eating poisonous cassava,

Table 3 Evolution in food poisonings and Symptoms among patients.

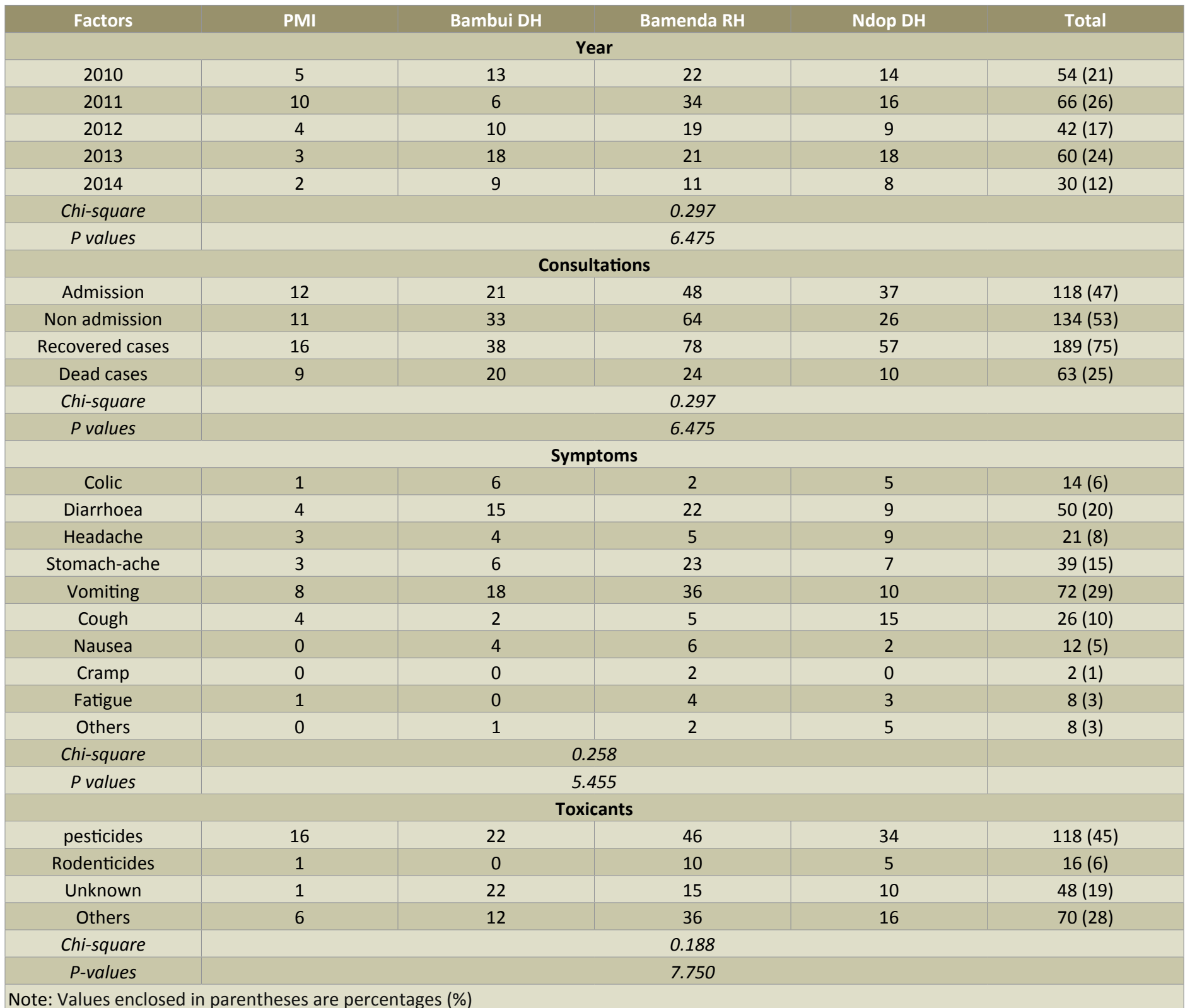


excess alcohol, kerosene, engine oil, drug overdose, detergents, disinfectants, and cosmetic products. Food in concern was of those commonly consumed in the community. But some cases were linked to direct intoxication by chemicals such as pesticides $(12 \%)$, engine oil, and detergents or drinking water (7\%). Achu (15\%); fufu corn (6\%); fresh cassava (16\%); plantains (5\%); sweet potatoes (18\%); beans (9\%); meat (5\%) were food more involved in various situations. No significant difference was statistically obtained amongst various contaminants presented by food poisoned patients (Chi-square; values $p$-values: 0.1887 .750 ).

When brought to hospital, the following drugs were administered: Bicarbonate (24\%), cipro (24\%), Metro (15\%), Dexa (3\%), paracetamol (8\%), N/S (10\%), Suppra (28\%), Soda (7\%), ammox (13\%), Glagyl (5\%), Cimentidine (8\%), Cloxaxine (7\%), Simine $(2 \%)$, Varimox $(2 \%)$, tracenmie $(4 \%)$. But sometimes before bringing the food intoxicated person to the hospital, home first aids treatments are given. They consist of drinking large amount of water ( $4 \%$ of cases), charcoal or Vegetable oil (16\%), milk (4\%) and other liquids either medicinal or not to extract poison by inducing vomiting or purging.

\section{Discussion}

A total of 323,169 patients were consulted during the five years records presented in this study. They are shared as followed: Bambui District Hospital (14\%), PMI Bamenda (22\%), Regional Hospital (56\%) and Ndop District Hospital (9\%). Then, food poisoned individuals represent about $0.08 \%$ of the total patients consulted. This high number indicates that food intoxication generally affects all family members since the contaminated meal is for the whole family [20]. Then, the probability for all family members to be transported to the hospital is high and generally one or two deaths may be registered since the toxicity of a substance depends on the weight of the consumer, chemical structure and the quantity of food consumed [21,22].

Food poisoning also varies with the severity of the pathogen because micro-organisms such as E. coli, Salmonella spp are food contaminants, pathogenic microorganisms, and can cause discomfort on consumers $[23,24]$. The equal prevalence between men and women is an indicator of sharing food and activities such as farming which can lead to chemical intoxication. The highest prevalence reported from the Regional Hospital (main hospital of the Region) reflects the ability of this hospital to handle critical health cases because of the skilled personnel and facilities. Ndop seems to be far from that main hospital and has recorded many cases. It is not well equipped but is used as main health center for the locality. According to observations of Murone et al. [25], children may be highly affected. Those highly poisoned are the youths, the most active group of people who are students and farmers with their children. Most of them manipulate pesticides in farms with no protective clothing [4,5]. Students work in farms as pesticides workers during their free period [18]. The food poisoned patients indicate that there is no exception among people wherever found in the Region, are concerned by food contaminants. However, the high prevalence comes from Mile 4, Bambui and Akum. Many other unreported cases have been noted in the same sectors. Poisoning from cereals is very common in Cameroon $[1,16,26]$. Akum is one of the sectors where many signs and symptoms from pesticides toxicity have been reported [17]. In that sector as in Santa, many farmers and pesticide sellers are ignorant of the toxicity of pesticides $[4,26]$. This can then be supported by the constant intoxication prevalence observed from 2010 to 2014.

Signs and symptoms presented by food intoxicated patients are similar to those described from a poisoned person [24-28]. It was mentioned that in some cases, the patient was dead before reaching the hospital. It has been realized that biological food poisoning is the most important intoxication form in Africa because of poor hygienic conditions [29]. But in this case, pesticides are more (51\%). This is similar to cases reported by Sonchieu [16] in Ngaoundere hospitals. At times it becomes difficult to distinguish symptoms from chemical intoxication to biological infection. So, only declarations of caretakers or patients themselves are taken into consideration to orientate the diagnosis of the disease and adequate treatment. A cross sectional survey conducted in Mile 4 and Akum confirm the high prevalence recorded in hospitals with cases from. Data collected from the two sectors (not presented in this study) through questionnaires show that chemical and biological food poisoning has been frequently happening among inhabitants. But chemical contamination is generally recognized by themselves since at time it is voluntary (suicide) or accidental during handling, manipulation, spraying or storage because some use their house to store pesticides used in farming [26,30]. At consumption, the removal of pesticide residues through washing, peeling or any domestic methods of decontamination such as cooking is not effective or not systematic as observed by Mead et al. and Bordet et al. [2,31]. Thus, it cannot be identified by populations as such: this needs laboratory analysis [10,32]. A Risk-based Food Safety Systems for Foodborne Infections and Intoxications developed by Caswell [33] can be applied to limit contamination of food. This ignorance will surely lead to developing non-communicable diseases such as cancer as described by Gold et al. [34] and Margaret et al. [35] as a result of non-respect of spraying parameters such as doses, date before harvesting, among others $[4,36,37]$. Contamination of these foods can also be attributed to microorganisms whose development is facilitated because of high water content increasing their perishability [26]. Treatments administered are indigenous (milk drinking, water, red oil) or artificial with all above listed compounds. Their action is to neutralize toxic compounds [38-40].

This study did not look for details regarding characteristics of the contaminants which is on line with the work of Sonchieu [16] Their effects on the systems of victims were not evaluated to appreciate the extent of their action. In addition, no traceability was carried out to identify the origin of the toxic except the small survey conducted in the most affected areas.

\section{Conclusion}

Two hundred and fifty-two cases of food intoxications registered in only four hospitals and reported in this study is very high. A 
systematic survey may bring out critical figures to stress more of the exposure risks that have been reported and described by many authors. Many cases that happened are locally managed and have never been reported to authorities or to hospitals for recording. Many inhabitants have to be more educated on good hygienic practices through a good implementation of KAPC (knowledge, attitude, practices and communication) to limit proliferation of pathogenic microorganisms or their toxins. Farmers need to be well trained on methods of handling, manipulating and storing pesticides since these chemicals are pointed to be responsible for many food poisoning cases.

\section{Summary Statement}

This study was carried out to bring light on the frequency of food intoxication cases recorded in main public hospitals of the North West Region of Cameroon; it comes out that, pesticides and

\section{References}

1 Ngamo LST, Hance T (2007) Diversité des ravageurs des denrées et méthodes alternatives de lutte en milieu tropical. Tropicultura 25: 215-220.

2 Bordet $F$ (2010) Food poisoning prevention in the setting of a cooking workshop. Soins Aides- Soignantes 32: 20-21.

3 Bencko V, Príkazská M (2010) Food-borne infections and intoxications. Prakticky Lekar 90: 274-279.

4 Sonchieu J, Ngassoum MB, Nantia AE, Laxman PS (2017) Pesticides applications on some vegetables cultivated and health implications in Santa, North West-Cameroon. SSRG Int J Agri Environ Sc 4: 39-46.

5 Pouokam GB, William LA, Alice SN, Mohamed ES (2017) A pilot study in cameroon to understand safe uses of pesticides in agriculture, risk factors for farmers' exposure and management of accidental cases. Toxics 5: 1-15.

6 Daoudou NZ, Tiku KP, Imele H, Mendi S, Foko J (2002) Microorganisms associated with of Colanuts (Cola nitida Vent Schott of Endlicher) in the North West Province of Cameroon. Master diss. University of Dschang, Cameroon.

7 Hamer DH, Gorbach SL (2008) Intestinal infections: Overview. In: International Encyclopaedia of Public Health. Academic Press, Oxford, UK.

8 Bough M (2013) Food-associated intoxications. Small Animal Toxicology Essentials. 547: 207-219.

9 Toldrá T, Fung DYC (2010) Microbial hazards in foods: Food-borne infections and intoxications. Handbook of Meat Processing. 28: 481-500.

10 International Programme on Chemical Safety (IPCS) (2009) Environmental Health Criteria 240 Principles and Methods for the Risk Assessment of chemicals in Food. In: Maximum Residue Limits for Pesticides and Veterinary Drugs. A joint publication of the Food and Agriculture Organization of the United Nations and the World Health Organization.

11 Hefnawy WF (2009) Sensitivity of Listeria monocytogenes to selected species. J Food Prot 56: 876-878.

12 Stockman W, Durnez P, Spoelders K (2008) Food intoxication. Tijdschrift voor Geneeskunde 64: 1091-1093.

13 Badarou S, Coppieters Y (2009) Endosulfan poisoning from food: A pathogenic micro-organisms are responsible for the most cases. This was done through data collected from registering books from the hospitals.

\section{Authors Contributions}

Sonchieu Jean contributed in organizing data, coordinating data collection and writing the paper; Azouline Michel collected data from the field and write the first draft of the paper; Ngassoum Martin supervised and oversaw the whole work and corrected the final draft of the paper before submission.

\section{Conflicts of Interest}

We authors declare that there no conflicts of interest for publishing this paper.

reporting and management system in Benin. Environment, Risques et Sante. 8: 133-136.

14 Biró G (2003) Foodborne infections and bacterial intoxications- A new-old challenge for food science and medicine. Acta Alimentaria 32: 119-123.

15 Tata E (2012) Estimating hygienic situation in the preparation of North West foods. Master dissertation, The University of Dschang.

16 Sonchieu J (2006) Selling pesticides in Ngaoundere, Cameroon. Crop Prot 48: 180-181.

17 Akum UL (2016) Pesticide handling and health implications on farmers in Santa sub-division. DIPES II dissertation, The University of Bamenda, Cameroon.

18 Zephania NF (2014) Montane resources exploitation and the emergence of gender issues in Santa economy of the western Bamboutos highlands, Cameroon. Int J Geo Reg Plan Res 1: 1-12.

19 National Institute of Statistics: North West Branch (NIS: NWB) (2015) Catalogue of statistics of the North West region of Cameroon.

20 Sinell HJ (1995) Control of food-borne infections and intoxications. Int J Food Microbiol 25: 209-217.

21 Wong HL, Garthwaite DG, Ramwell CT, Brown D (2018) Assessment of exposure of professional agricultural operators to pesticides. Sci Total Environ 1: 874-882.

22 Glaizal M, Schmitt C, Tichadou L, Sapori JM, Hayek-Lanthois M, et al. (2013) Food poisonings related to organic buckwheat contaminated with Datura sp.: A poison control and toxicovigilance center activity 42: 1412-1415.

23 Fleurette J (1991) Staphylococcal food poisoning. La revue de référence infirmière $547: 23-25$.

24 Marzhokhova MY, Zhelikhazheva ZM (2009) Evaluation of the endogenous intoxication syndrome in food toxic infections. Klinichescheskaya Laboratornaya Diagnostika 1: 15-18.

25 Batty GD, Kivimäki M, Bell S, Gale CR, Shipley M, et al. (2018) Psychosocial characteristics as potential predictors of suicide in adults: An overview of the evidence with new results from prospective cohort studies. Translat Psychiat 8: 00728.

26 Bouvet JM (1991) Salmonella food poisoning. La revue de reference infirmiere 547: 26-28. 
27 Murone AJB, Stucki P, Roback MG, Gehri M (2005) Severe methemoglobinemia due to food intoxication in infants. Pediatr Emerg Care 21: 536-538.

28 Sonchieu J, Akono EN, Ngwamitang CT, Ngassoum MB (2018) Heath risk amongst pesticides sellers in Bamenda (Cameroon) and peripheral areas. Environ Sci Pollut Res 1: 1-7.

29 Gaulin C (1993) Food poisoning caused by a chemical product. Union Medicale du Canada 122: 354-356.

30 Jeon U, Park S, Park S, ELee Y, Gil HW (2018) Clinical characteristics of stress cardiomyopathy in patients with acute poisoning. Scient Rep 8: 223.

31 Ngoko Z, Marasas WFO, Rheeder JP, Sherphard GS, Wingfield MJ (2001) Fungal infection and mycotoxin contamination of maize in the humid forest and the western highlands of Cameroon. Phytoparasitica 29: 352-360.

32 Matthews GA, Dobson HM, Wiles TL, Warburton H (2003) The impact of pesticide application equipment and its use in developing countries, with particular reference to residues in food, environmental effects and human safety. FAO 8: 15-25.

33 Mead PS, Slutsker L, Dietz V (1999) Centers for disease control and prevention, food-related illness and death in the USA. Emerging Infectious Dis 5: 607-625.
34 Gerage JM, Ana GMP, Marina SV (2017) Food and nutrition security: Pesticide residues in food. Nutrire 42: 3-7.

35 Caswell JA (2013) Development of risk-based food safety systems for foodborne infections and intoxications. Foodborne Infect Intoxic 1: 53-64.

36 Gold LS, Slone TH, Ames BN, Manley NB (2010) Pesticide residues in food and cancer risk: A critical analysis. In: Handbook of pesticide toxicology, (2nd edn), Academic Press, San Diego, California, USA.

37 Margaret S, Donald C, Kathleen K, Cathy V, Luz HS, et al. (2004) Pesticide health effects and children. System Rev Pesticide Hum Health Effects 8: 167-169.

38 Taha RR, Alghalibi SM, Saeed SMG (2013) Salmonella spp. in patients suffering from enteric fever and food poisoning in Thamar City, Yemen. Eastern Mediterranean Health J 19: 88-93.

39 World Health Organization (WHO) Statistical information on foodborne disease-microbiology and chemical hazards, FAO/WHO PanEuropean conference on food safety and quality, Budapest. pp: 2528 February 2002, Hungary.

40 Jean S, Ngassoum MB, Tchatchueng JB, Srivastava AK, Srivastava LP (2010) Survey of pesticide residues in maize, cowpea and millet from northern Cameroon. Food Additives Contam 3: 178-184. 